\title{
Urban poor women do not increase their diet during pregnancy: A study from an urban resettlement colony in Delhi, India
}

\section{Rakesh Kumar, O. P. Aslesh', Anjali ${ }^{2}$, Anushka Kapoor ${ }^{2}$, Divya Sanan², Esha Wadhwa², Neha Agarwal ${ }^{2}$}

Centre for Community Medicine, AlIMS, New Delhi,

1 Department of Community Medicine, Academy of Medical Sciences, Pariyaram, Kerala, ${ }^{2}$ Food and Nutrition, Lady Irwin

College, New Delhi, India

Address for the Correspondence:

Dr. Rakesh Kumar, Senior Programme Officer, Indian Coalition for Control of lodine Deficiency

Disorder (ICCIDD), Centre for

Community Medicine, Old OT Block, AlIMS, New Delhi - 110 029,

India.

E-mail: dr.rakesh3105@gmail.com

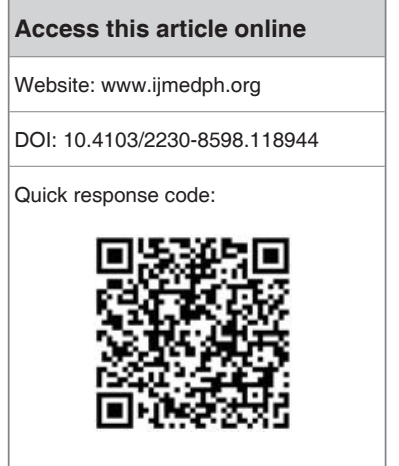

Background: The rate of decline in maternal and infant mortality in India is not fast enough to achieve Millennium Development Goals. Poor nutrition, during pregnancy is associated with adverse maternal and fetal outcomes. However, due to various factors, pregnant women do not enhance the quality or quantity of diet during pregnancy. Aims: This study was conducted to find whether increase in dietary intake occurs in pregnancy and to understand the factors influencing the dietary intake during pregnancy in an urban resettlement colony in Delhi. Materials and Methods: Community based case control was conducted among 50 pregnant women and 50 matched controls to study the change in dietary intake during pregnancy and its determinants. In-depth interview were conducted among pregnant women to understand the factors influencing the dietary intake. Results: No significant difference in the intake of energy, protein, iron, calcium, protein, folic acid and Vitamin $\mathrm{C}$ between pregnant and non pregnant women. The factors like age, family type, history of previous pregnancy and socio economic status were not associated with increase in dietary intake in pregnancy. In-depth interview shows that even though pregnant women knew that dietary intake should increase in pregnancy, they fail to put this into practice. Conclusions: The pregnant women in the urban resettlement colony do not eat differently from their non pregnant counterpart.

Key words: Dietary intake, India, pregnant women, urban

\section{INTRODUCTION}

Child and maternal mortality is global health priority as enunciated by Millennium Development Goals (MDG) 4 and 5. The target is to reduce the under five mortality by two third and maternal mortality by three fourths in each country as compared to 1990 . Though child and maternal mortality is declining world over, the rate of decline is not enough to achieve the target by $2015 .{ }^{[1,2]}$ India has made substantial progress in reducing child and maternal mortality. While the under 5 mortality rate has fallen from 112 per 1000 live births in 1990 to 66 per 1000 live births, maternal mortality ratio has fallen from 437 per 100,000 live births in 1992 to 212 per 100,000 live births in 2009 but it is still far from achieving the MDG 4 and $5 .{ }^{[3]}$ There is also gross regional variability in childhood and maternal morbidity and mortality rates. ${ }^{[4]}$ Energy and micro-nutrient deficiency in pregnancy can lead to intra uterine-growth retardation, low birth weight, preterm delivery, birth defects, reduced physical and mental potential of the child and neonatal death. ${ }^{[5]}$ Also, poor maternal nutritional would lead to anemia in pregnancy which is recognized as an important cause of maternal mortality in India. ${ }^{[6]}$ As per Indian Council of Medical Research recommendation, a pregnant woman should increase the energy intake by $350 \mathrm{~K}$ cal and protein intake by $23 \mathrm{gm}$ in addition to the normal recommended intake. ${ }^{[7]}$ Several studies, have been carried out in India to find the nutrient deficit in the pregnant women. ${ }^{[8-14]}$ These studies compared the observed intake in pregnancy with the recommended intake and reported insufficient nutrient intake during pregnancy. However, the studies exploring increase in dietary intake during pregnancy as compared with non pregnant state are limited. Also, to plan effective nutrition intervention strategy, it is required to understand the behaviour pattern of pregnant women in regard to nutrition. Therefore, this study was planned to study the increase in dietary intake and its determinants in pregnant women and to understand the factors influencing the dietary intake during pregnancy. 


\section{MATERIALS AND METHODS}

The study was conducted in six randomly chosen blocks of Dr. Ambedkar Nagar, a resettlement colony in south Delhi in June 2011. In this area, health care services are provided by a Maternal and Child Health Clinic of Municipal Corporation of Delhi and a Mobile Health Clinic from Centre for Community Medicine, All India Institute of Medical Sciences, New Delhi. A community based case control study was carried out to study the dietary intake during pregnancy and its determinants. Pregnant women, who were diagnosed by positive urine pregnancy test after 6 weeks of amenorrhoea were taken as cases. Dietary intake among pregnant women was compared with matched non-pregnant, non lactating women with no history of amenorrhoea of 6 weeks duration or child birth within span of one year to assess increase in nutrient intake during pregnancy. Non-pregnant state among controls was confirmed by a negative result on the urine pregnancy test. In order to detect a mean difference equal to the earlier recommended additional energy required during pregnancy (300 Kcal) with a power of $95 \%$ and type I error of $5 \%$, given a standard deviation of $410 \mathrm{kcal}$ as seen in study by Gautam et al., ${ }^{[7]}$ the sample size in each group were calculated to be 50 . All pregnant women in the study area were enumerated through house to house surveys and records of antenatal clinics. There were a total of 130 pregnant women in the area at the time of this study, out of which 50 were randomly selected and included in the study. An equal number of non-pregnant and non lactating women of same age group were selected as control. Controls were selected from the same household as of cases or from the adjacent house if nobody was available in the same household. Matching was done for age, occupation and socio-economic status. Socio-economic status was assessed using modified Kuppuswamy scale. ${ }^{[15]}$ Pregnant and non pregnant women with co morbid conditions were excluded from the study. A structured interview schedule was used to collect socio-demographic characteristics of the participants. Twenty four hours recall method was used to calculate the nutrient intake. The 24 -h recall conducted consisted of a detailed discussion of what foodstuffs and dishes had been eaten and in what quantity during the preceding day. It was conducted for 2 different days in order to check the differences in the eating patterns in two days. The visits were unannounced. Food intake was not measured on festival days, when special foods are eaten. To serve as a framework of the dietary interview the general idea of the previous day's mealtimes and types of meals was first discussed. The interview then progressed in chronological order, beginning with the first meal eaten by the women. All the foodstuffs and dishes and their amounts were recorded meal by meal. The interviewee was allowed to designate the size of the servings by units of weight, volume or household measure or with the aid of the food models. Conversion to grams was done later using the standardized measurements in connection with the coding. Dry spices and condiments were not included in calculations. To understand the factors influencing the dietary intake in-depth interview were conducted among pregnant women attending antenatal clinics. Purposive sampling was done to recruit subjects for in-depth interview. A pretested in-depth interview in local language was used. It included questions regarding physical changes felt after getting pregnant, influence of work on dietary intake, perceptions about daily dietary intake, cultural beliefs and food choices. They were also asked about utilization of Anganwadi which is an initiative by government of India to provide supplementary nutrition to preschool children and pregnant women. ${ }^{[16]}$ A total of 25 women in second and third trimester were interviewed. They were provided with dietary counselling, medications and appropriate referral when required after the data collection. Ethical principles of the Helsinki Declaration were fully complied with and confidentiality of the information was maintained. All the study participants were explained about the purpose, objectives and the methodology of the study and written consent for participation in the study was obtained from them.

\section{Statistical Analysis}

The quantitative data were entered in Microsoft excel 2007. For the analysis, amount of raw food in each dish were estimated. From the estimated amount of raw food consumed, the daily intake of energy, protein, iron, calcium, folic acids, vitamin $\mathrm{C}$ and fibre were calculated using the standard nutritive value of various raw Indian food. ${ }^{[17]}$ Data were analysed using SPSS version 13 . Variables were tested for normal distribution using a Shapiro-Wilk test. As the food and energy/nutrient intake were not normally distributed, the results were described in median with interquartile range. Percent adequacy of intake of different nutrients in both the groups was expressed as a percentage of recommended daily allowances for pregnant and non pregnant women. Mann Whitney $U$ test for quantitative variables and chi square test for qualitative variables were used to test for any significance between the groups and $P$ value less the 0.05 were used to indicate statistical significance. For the analysis of in-depth interviews, they were at first transcribed using the recordings and the notes taken. They were translated to English and the opinions were sorted, categorised and coded manually to categorise data. Key themes were identified from the transcriptions. When similar information was given by many participants, they were grouped and described verbally. When some women gave very different information, this was described if considered important.

\section{RESULTS}

A total of 50 pregnant women and 50 matched non-pregnant controls were included in the study. The mean age of pregnant women and the non-pregnant women was 24.6 years (SD- 4.1) and 27.4 years (SD-6.5) respectively. Mean parity of pregnant and non-pregnant women was 1.68 (SD-1.7) and 1.15 (SD-1.2) respectively and the difference was not-significant $(P=0.083)$. There was no significant difference between pregnant and non pregnant women in terms of education status, occupation and socio economic status [Table 1].

The median intake of pulses was higher in pregnant women (35 gm) when compared to non pregnant women ( $30 \mathrm{gm})$ but the difference was not statistically significant $(P=0.2)$. Intake of cereals, vegetables 
and dairy products were lower in pregnant women when compared to non pregnant women, but again the result was not statistically significant. The median intake of fruits, meat and poultry products were nil in both the groups [Table 2]. The median energy intake among pregnant women was 1301.3 Kilocalories (kcal) and that among non pregnant was $1250.3 \mathrm{Kcal}$; however the difference was not statistically significant $(P=0.43)$. Main source of energy were cereals. The intake of energy in pregnant women in first trimester $(1057 \mathrm{Kcal})$ were lower than those in second $(1334 \mathrm{Kcal})$ and third trimester $(1250 \mathrm{Kcal})$, but the difference was not significant. There was no significant difference between the two groups in terms of intake of protein and fat. Median intake of iron, calcium, vitamin C and folic acid in pregnant women were $10.8 \mathrm{mg}$, calcium $333.7 \mathrm{mg}, 211.6 \mathrm{mg}$ and 43.5 micro gm respectively and were found to be lower than that of non pregnant women, but the result were not statistically significant [Table 3]. The median energy and protein intake were found to be higher in pregnant women belonging to lower socio-economic class (+213 kcal, $+12.7 \mathrm{gm}$ ) and marginally low in middle and upper socio economic class $(-14.6 \mathrm{Kcal},-1.7 \mathrm{gm})$ when compared to non pregnant women of the same class, but the difference were not statistically

\begin{tabular}{|c|c|c|c|}
\hline Characteristics & $\begin{array}{c}\text { Non pregnant } \\
\text { women }(n=50) \\
(\%)\end{array}$ & $\begin{array}{c}\text { Pregnant } \\
\text { women }(n=50) \\
(\%)\end{array}$ & $P$ value \\
\hline \multicolumn{4}{|c|}{ Education of participants } \\
\hline Illiterate & $5(10)$ & $8(16)$ & 0.554 \\
\hline Literate & $45(90)$ & $42(84)$ & \\
\hline \multicolumn{4}{|l|}{ Occupation } \\
\hline Homemaker & $46(92)$ & $49(98)$ & 0.362 \\
\hline Employed & $4(8)$ & $1(2)$ & \\
\hline \multicolumn{4}{|c|}{ Socio economic status } \\
\hline Upper & $2(4)$ & $1(2)$ & 0.715 \\
\hline Upper middle & $13(26)$ & $17(34)$ & \\
\hline Middle & $20(40)$ & $18(36)$ & \\
\hline Upper lower & $15(30)$ & $13(26)$ & \\
\hline Lower & 0 & $1(2)$ & \\
\hline \multicolumn{4}{|l|}{ Age category } \\
\hline$<25$ & $26(52)$ & $35(70)$ & 0.14 \\
\hline$>25$ & $24(48)$ & $15(30)$ & \\
\hline \multicolumn{4}{|l|}{ Trimester } \\
\hline 1 & NA & $4(8)$ & NA \\
\hline 2 & NA & $21(42)$ & \\
\hline 3 & NA & $25(50)$ & \\
\hline
\end{tabular}

significant [Table 4]. Also, energy and protein intake in pregnant women belonging to joint family $(+172.3 \mathrm{Kcal},+11.2 \mathrm{gm})$ were found to be higher and those belonging to nuclear family $(-41 \mathrm{Kcal}$, $-2.5 \mathrm{gm}$ ) were lower than non pregnant women but the result were not significant. There was also no significant difference in energy or protein intake between pregnant and non pregnant women belonging to different age group, education status or with history of previous pregnancy. Proportion of pregnant women with adequacy more than $90 \%$ of the recommended for energy and protein intake was $8.0 \%$ and $29.2 \%$, respectively. Percent adequacy less than $50 \%$ of the recommended energy intake was around 35\% of pregnant women and $16.3 \%$ of non pregnant women. Protein intake was less than half the recommended value in $21 \%$ of pregnant women and $4 \%$ of non pregnant women. The daily intake of iron was less than half of the recommended in $96 \%$ of the pregnant women. The daily intake of calcium and folic acid were less than half of the recommended intake in $90 \%$ and $70 \%$ of the pregnant women [Table 5]. In the In-depth interviews, when the questions regarding change in dietary intake were asked, half of the pregnant women mentioned that they have increased their intake. Women who had increased their intake mentioned that they have increased their intake on advice of doctor or family members. Those who had decreased their intake did so due to problem of vomiting and nausea and they didn't feel like eating anything. Some cases has reduced their intake as after doing work they get tired very soon and hence don't feel like eating anything or the women who cooks by herself don't feel like cooking for herself.

"After doing work I don't feel like cooking for myself".

Regarding the role of family and customs is influencing their dietary pattern, women stated that while they were asked to restrict some of the food items during pregnancy, intake of some are also encouraged by their family members. Restricted food items include papaya, egg and chicken. Egg and chicken were considered as hot foods. Papaya was being restricted because of the belief that it can lead to miscarriage. In few cases it was seen that the hot temperature foods were also being restricted like 'hot milk'. The reasons for the restrictions were that it will lead to heartburn and vomiting. Foods that were being encouraged by the family were milk and milk products, fruits, green leafy vegetables, honey and jaggery. It was observed that maximum subjects ate according to their families wish rather than what they desired to eat. Food restriction was not practiced by women belonging to nuclear family. When they were asked about the ritual fasting during this time almost every pregnant woman mentioned that they are not

\begin{tabular}{|c|c|c|c|c|c|}
\hline & Pregnant women & Inter quartile range & Non pregnant women & Inter quartile range & $P$ value \\
\hline Cereals & 190.0 & 111.3 & 202.5 & 85.6 & 0.3 \\
\hline Pulses & 35.0 & 45.3 & 30.0 & 29.3 & 0.2 \\
\hline Vegetable & 153.8 & 196.5 & 201.3 & 231.6 & 0.1 \\
\hline Fruits & 0.0 & 42.5 & 0 & 26.3 & 0.2 \\
\hline Meat/fish/egg & 0.0 & 0.0 & 0 & 2.6 & 0.7 \\
\hline Dairy & 63.8 & 80.0 & 65.0 & 90.0 & 0.9 \\
\hline Oil/butter/ghee & 12.5 & 7.5 & 13.8 & 7.5 & 0.6 \\
\hline
\end{tabular}




\begin{tabular}{|c|c|c|c|c|c|}
\hline & Pregnant women & Inter quartile range & Non pregnant women & Inter quartile range & $P$ value \\
\hline Energy (Kcal) & 1301.3 & 520.2 & 1250.3 & 377.9 & 0.7 \\
\hline Protein (gm) & 42.6 & 28.3 & 41.7 & 14.4 & 0.4 \\
\hline Fat (gm) & 27.4 & 16.9 & 26.9 & 13.1 & 0.8 \\
\hline Iron (mg) & 9.5 & 7.1 & 10.7 & 5.1 & 0.8 \\
\hline Calcium (mg) & 299.2 & 45.8 & 293.0 & 123.9 & 0.7 \\
\hline Vitamin C (mg) & 36.2 & 45.8 & 45.6 & 51.1 & 0.1 \\
\hline Folic acid (uGu) & 22.4 & 16.4 & 23.6 & 12.7 & 0.1 \\
\hline Fibre (mg) & 173.1 & 153.3 & 152.8 & 154.7 & 0.7 \\
\hline
\end{tabular}

\begin{tabular}{|c|c|c|c|c|c|c|}
\hline & \multicolumn{3}{|c|}{$\begin{array}{l}\text { Energy intake kilocalories } \\
\text { (Interquartile range) }\end{array}$} & \multicolumn{3}{|c|}{$\begin{array}{l}\text { Protein intake in grams } \\
\text { (Interquartile range) }\end{array}$} \\
\hline & Non pregnant & Pregnant & $P$ value & Non pregnant & Pregnant & $P$ value \\
\hline \multicolumn{7}{|l|}{ Age } \\
\hline$<25$ years & $1243.4(445.7)$ & $1264.1(474.7)$ & 0.9 & $42.7(16.9)$ & $39.8(26.2)$ & 0.9 \\
\hline$>25$ years & $1240.5(333.9)$ & $1385.2(565.7)$ & 0.3 & $40.4(11.8)$ & $47.4(30.6)$ & 0.2 \\
\hline \multicolumn{7}{|l|}{ Socio economic status } \\
\hline Lower/Upper lower & $1256.1(333.8)$ & $1469.9(547.3)$ & 0.1 & $41.2(18.7)$ & $53.9(31.6)$ & 0.3 \\
\hline Middle and above & $1244.5(455.3)$ & $1229.9(473.5)$ & 0.8 & $41.8(18.7)$ & $40.1(23.6)$ & 0.6 \\
\hline \multicolumn{7}{|l|}{ Education } \\
\hline Illiterate/Primary school & $1236.6(333.8)$ & $1430.5(357.4)$ & 0.1 & $39.2(11.9)$ & $48.8(33.8)$ & 0.2 \\
\hline Middle school and above & $1264.1(580.4)$ & $1229.9(571.8)$ & 0.7 & $42.3(15.8)$ & $40.4(25.2)$ & 0.9 \\
\hline \multicolumn{7}{|l|}{ Type of family } \\
\hline Nuclear & $1238.4(571.2)$ & $1197.7(541.6)$ & 0.7 & $42.0(14.2)$ & $39.5(23.8)$ & 0.9 \\
\hline Joint & $1271.6(340.7)$ & $1443.9(497.5)$ & 0.2 & $39.7(14.3)$ & $50.9(24.4)$ & 0.1 \\
\hline \multicolumn{7}{|l|}{ History of previous pregnancy } \\
\hline Yes & $1256.1(307.9)$ & $1249.9(413.3)$ & 0.5 & $42.3(8.8)$ & 40.9 (24.9) & 0.9 \\
\hline No & $1210.2(546.8)$ & $1467.0(665.7)$ & 0.2 & $40.8(18.9)$ & $49.7(31.1)$ & 0.2 \\
\hline
\end{tabular}

\begin{tabular}{|c|c|c|c|c|c|c|c|}
\hline \multirow[t]{2}{*}{ Nutrients } & \multicolumn{2}{|c|}{$\begin{array}{c}<50 \% \text { of the recommended } \\
\text { intake (\%) }\end{array}$} & \multicolumn{2}{|c|}{$\begin{array}{l}50-90 \% \text { of the recommended } \\
\text { intake (\%) }\end{array}$} & \multicolumn{2}{|c|}{$\begin{array}{c}>90 \% \text { of the recommended } \\
\text { intake (\%) }\end{array}$} & \multirow[t]{2}{*}{$P$ value } \\
\hline & $\begin{array}{l}\text { Non pregnant } \\
\text { women }\end{array}$ & $\begin{array}{l}\text { Pregnant } \\
\text { women }\end{array}$ & $\begin{array}{l}\text { Non pregnant } \\
\text { women }\end{array}$ & $\begin{array}{l}\text { Pregnant } \\
\text { women }\end{array}$ & $\begin{array}{l}\text { Non pregnant } \\
\text { women }\end{array}$ & $\begin{array}{l}\text { Pregnant } \\
\text { women }\end{array}$ & \\
\hline Calorie & 16.0 & 34.0 & 72.0 & 58.0 & 12.0 & 8.0 & 0.11 \\
\hline Protein & 4.0 & 20.8 & 66.0 & 50.0 & 30.0 & 29.2 & 0.03 \\
\hline Fat & 0 & 0 & 9.1 & 52.1 & 90.9 & 47.9 & $<0.01$ \\
\hline Calcium & 14.3 & 89.8 & 57.1 & 10.2 & 28.6 & 0 & $<0.05$ \\
\hline Iron & 0 & 0 & 12.2 & 4 & 87.8 & 96 & 0.13 \\
\hline Folic acid & 28.3 & 69.4 & 39.1 & 22.4 & 32.6 & 8.2 & $<0.05$ \\
\hline
\end{tabular}

advised to do fast at this time, except very few cases who fasted.

"I fasted because; otherwise the chain of fasting would have been disrupted".

Regarding their knowledge about Anganwadi, most cases were aware of the existence of Anganwadi in their area but they didn't go there. They are under the notion that food is provided to only children in these centers and were not aware that pregnant women also receive supplementary nutrition from Anganwadi.

"Yes I have heard about anganwadis. They provide porridge, boiled rice and chana for children".
Some pregnant women commented that even though the staff in Anganwadi had visited their house for registration, no information about the supplementary nutrition was provided to them.

\section{DISCUSSION}

The study showed that dietary intake in pregnant women in urban resettlement colony is not very different from their non pregnant counterpart in terms of food group and nutrient intakes. When compared to Recommended Daily Allowance (RDA) the observed intake of energy, protein, iron, calcium, vitamin $\mathrm{C}$ and folic acid was low in both pregnant and non pregnant women. The low calorie 
intake among both pregnant and non-pregnant women could be because of low socio-economic status as most of the subjects were from upper lower or middle socio-economic status. Inadequate knowledge regarding appropriate dietary intake could be another possible explanation.

The median energy intake in pregnant women in the present study was found to be $1301 \mathrm{Kcal}$. This was considerably lower than that found in other similar studies which had used the dietary recall method for dietary assessment. The study by Kapil et al., among pregnant women in urban slums showed that the mean energy intake in pregnant women was $1500 \mathrm{Kcal}^{\left[{ }^{[1]}\right]}$ Other studies were for rural areas and showed mean energy consumption between 1541 to

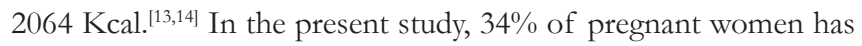
energy intake less than half of the recommended value while the proportion was $18 \%$ in the study by Kapil et al., ${ }^{[11]}$ Similarly the median protein intake was $42 \mathrm{gm}$ in the present study. The result was similar to other studies where in the mean protein intake was found to lie between $41-47 \mathrm{gm} .{ }^{[13,14]}$ The dietary intake of the iron, folic acid, vitamin $\mathrm{C}$ and calcium in pregnant women were found to be same as in non pregnant women and were alarmingly low in comparison to the recommended intake. The median iron intake was less than $10 \mathrm{mg}$ and $96 \%$ were having dietary intake less than $50 \%$ of the recommended. This is similar to other studies where the mean intake ranged from $10 \mathrm{gm}$ to $15 \mathrm{gm}$. The median calcium intake was $293 \mathrm{mg}$ in pregnant women and this was low when compared to study by Anderson et al., which showed a mean intake of $523 \mathrm{mg}{ }^{\left[{ }^{10]}\right.}$ The low intake of calcium in the present study is due low intake of dairy product (63 gm) compared to $129 \mathrm{gm}$ in the study by Anderson et al., which was done in rural area. This result should be interpreted under the light that the iron, folic acid and calcium supplements provided as supplements were not considered in the analysis. In the present study intake of vegetables were low in pregnant women when compared to the non pregnant women. Also the median intake of fruits were nil in both the groups. Also intake of meat and fish was nil in both the group. This has resulted in low intake of micronutrients like iron, Vitamin C and folate in both the groups. These results are similar to the results of the study done by Pathak et al., which showed that consumption of food groups rich in micronutrients was infrequent among the pregnant women. ${ }^{[8]}$ Similar results were also shown in a study where consumption of cereals, pulses, vegetables, fats and oils, sugar and jaggery and milk and milk products by the pregnant women were less than the values of recommended dietary allowances (RDA) of Indian Council of Medical Research (ICMR). ${ }^{[18]}$

In the study about one third of the pregnant women has energy and protein adequacy less than $50 \%$ of the recommended intake. This was far less when compared to percent adequacy of energy and protein intake in rural areas $(7.5 \%$ and $18.5 \%) \cdot{ }^{[19]}$ Percent adequacy of nutrient intake was found to be low in pregnant women when compared to non pregnant women [Table 5]. This is because as recommended dietary intake is more in pregnant women, but the pregnant women in the study area is not increasing in dietary intake in comparison to their non pregnant counterpart. In the qualitative study, most pregnant women have said that that they have increased their dietary intake as advised by either family members or health personal. The practice of eating low in pregnancy as found in the study by Hutter et al., in rural area was not seen in the present study. ${ }^{[13]}$ Also there was very minimal food restriction in the present study. In spite of this, dietary intake was similar to non pregnant women as seen in the case control study. This shows that a gap in knowledge about how much extra diet should be consumed in pregnancy. In the present study, as majority of pregnant participants are taking less than $80 \%$ of recommended nutrient intake, they are at a high risk of delivering low birth weight baby. ${ }^{[20]}$ In India, low birth weight is highly prevalent among pregnant women belonging to lowest wealth quintile and is accountable for up to one third of neonatal death. Also low dietary intake of iron as seen in the study, results in failure to meet the increased iron requirement in pregnancy resulting in anemia. Currently, $56 \%$ of pregnant women in India are anemic and $19 \%$ of maternal deaths are caused indirectly by anemia. ${ }^{[5]}$ Thus to achieve the MDG goal of reducing child and maternal mortality, the health programmes in India should give more attention on maternal nutrition. At present, the programmes are focused on providing supplementary nutrition through Anganwadi centres (ICDS), Iron Folic Acid (IFA) supplementation and cash incentives for buying food (Janani Suraksha Yojna). However, the utilization of these services is very low. Among the pregnant women in the lowest quintile, about $50 \%$ don't receive IFA tablets and $75 \%$ of pregnant women don't receive supplementary nutrition through Anganwadi. ${ }^{[2]}$ In the study, certain related issues came up like the lack of awareness about supplementary nutrition given through Anganwadi centre despite the accessibility. This was one of the few studies in India that compares the dietary intake in pregnant and non pregnant state which enables to observe any increase in food intake during pregnancy. The study had certain limitations which should be considered while interpreting the result. First, the power was set to detect a difference of $300 \mathrm{Kcal}$ between the pregnant and non pregnant group and thus small differences found in intake of other nutrients and also in subgroup analysis were proved to be non significant. Second, the study was not longitudinal and thus it was not able to detect the difference in dietary intake in pregnant and non pregnant state in the same person. Thirdly, in the study only $24 \mathrm{~h}$ recall method was used and was not supplemented by other methods like the weighing of food items as used in the study by Anderson et al. However, use of food models helped in precise estimation of food intake.

\section{CONCLUSIONS}

The study shows, that the pregnant women living in urban poor areas do not increase their dietary intake in pregnancy. Thus, there is a need to educate women regarding amount of food that should be consumed in pregnancy. Health education can be provided through mass media regarding the how to increase dietary intake in pregnancy. Also health personnel should practice providing diet plan comprising of locally available and affordable food items to pregnant women during routine antenatal checkups. Also, efforts to increase awareness 
about different services provided by Anganwadi for pregnant women should also be undertaken to increase the utilization.

\section{REFERENCES}

1. Murray CJ, Laakso T, Shibuya K, Hill K, Lopez AD. Can we achieve Millennium Development Goal 4? New analysis of country trends and forecasts of under-5 mortality to 2015 . Lancet 2007;370:1040-54.

2. Rajaratnam JK, Marcus JR, Flaxman AD, Wang H, Levin-Rector A, Dwyer L, et al. Neonatal, postneonatal, childhood, and under-5 mortality for 187 countries, 1970-2010: A systematic analysis of progress towards Millennium Development Goal 4. Lancet 2010;375:1988-2008.

3. Chatterjee A, Paily VP. Achieving millennium development goals 4 and 5 in India. BJOG 2011;118(Suppl 2):47-59.

4. Lahariya C, Paul VK. Burden, differentials, and causes of child deaths in India. Indian J Pediatr 2010;77:1312-21.

5. Abu-Saad K, Fraser D. Maternal nutrition and birth outcomes. Epidemiol Rev 2010;32:5.

6. Maternal Mortality in India 1997-2003. Available from: http://mp.gov.in/ health/Maternal_Mortality_in_India_1997-2003.pdf. [Last accessed on 2012 Oct 2].

7. Indian Council of Medical Research. Nutrient requirements and recommended dietary allowances for Indians; New Delhi, 2010. p. 255.

8. Gautam VP, Taneja DK, Sharma N, Gupta VK, Ingle GK. Dietary aspects of pregnant women in rural areas of Northern India. Matern Child Nutr 2008;4:86-94.

9. Pathak P, Kapil U, Kapoor SK, Saxena R, Kumar A, Gupta N, et al. Prevalence of multiple micronutrient deficiencies amongst pregnant women in a rural area of Haryana. Indian J Pediatr 2004;71:1007-14.

10. Jood S, Bishnoi S, Khetarpaul N. Nutritional status of rural pregnant women of Haryana State, Northern India. Nutr Health 2002;16:121-31.

11. Kapil U, Pathak P, Tandon M, Singh C, Pradhan R, Dwivedi SN. Micronutrient deficiency disorders amongst pregnant women in three urban slum communities of Delhi. Indian Pediatr 1999;36:983-9.
12. Andersen LT, Thilsted SH, Nielsen BB, Rangasamy S. Food and nutrient intakes among pregnant women in rural Tamil Nadu, South India. Public Health Nutr 2003;6:131-7.

13. Hutter I. Reduction of food intake during pregnancy in rural south India. Trop Med Int Health 1996;1:399-405.

14. Panwar B, Punia D. Nutrient intake of rural pregnant women of Haryana state, northern India: Relationship between income and education. Int J Food Sci Nutr 1998;49:391-5.

15. Kumar N, Shekhar C, Kumar P, Kundu AS. Kuppuswamy's socioeconomic scale Updating for 2007. Indian J Pediatr 2007;74:1131-2.

16. Integrated Child Development Services [Internet]. Available from: http:// wcd.nic.in/icds.htm [Last accessed on $2012 \mathrm{Apr}$ 1].

17. Gopalan C, Ramashastri BV, Balasubramanian SC. Nutritive Value of Indian Foods. Indian Council of Medical Research, National Institute of Nutrition: Hyderabad; 2002. p. 186.

18. Reddy NS, Sahani MJ, Pandey V. A longitudinal study on the food and nutrient intake of pregnant women. Indian J Nutr Diet 1994;31:235-40.

19. Rao KM, Balakrishna N, Arlappa N, Laxmaiah A, Brahmam GN. Diet and nutritional status of women in India. J Hum Ecol 2010;29:165-70.

20. Negandhi PH, Negandhi HN, Zodpey SP, Ughade SN, Biranjan JR. Risk factors for low birth weight in an Indian urban setting: A nested case control study. Asia Pac J Public Health 2011 [In press]. Available from: http:// aph.sagepub.com/content/early/2011/12/08/1010539511431486 [Last accessed on 2012 Oct 2].

21. International Institute for Population Sciences (IIPS) and Macro International. National Family Health Survey (NFHS-3), 2005-06. Vol. 1. Mumbai, India; 2007. p. 303.

How to cite this article: Kumar R, Aslesh OP, Kumar A, Kapoor A, Sanan D, Wadhwa E, et al. Urban poor women do not increase their diet during pregnancy: A study from an urban resettlement colony in Delhi, India. Int J Med Public Health 2013;3:134-9.

Source of Support: Nil, Conflict of Interest: None declared. 